\title{
Electronic effects in tautomeric equilibria: The case of chiral imines from D-glucamine and 2-hydroxyacetophenones ${ }^{\dagger}$
}

Received 00th January 20xx, Accepted 00th January 20xx DOI: $10.1039 / x 0 x \times 00000 x$

\begin{abstract}
Esther Matamoros, ${ }^{a *}$ Pedro Cintas, ${ }^{a}$ Mark E. Light ${ }^{b}$ and Juan C. Palacios ${ }^{a *}$
A one-pot procedure for preparing a series of chiral imines by direct condensation of D-glucamine with 2hydroxyacetophenones is described. Under conventional acetylation an unexpected mixture of two different peracetylated molecules is obtained, one with an open enamine structure, and the other incorporating an $N$-acetyl-1,3-oxazolidine into the acyclic skeleton. Surprisingly, both molecules coexist within the crystal's unit cell, as inferred from single-crystal X-ray analysis of a 5-bromo-substituted aryl derivative. Moreover, the 1,3-oxazolidine ring exists as rotational conformers $(E, Z)$ owing to the restricted rotation around the $N$-acetyl bond. The equilibrium involving imine and enamine structures has been assessed in detail, providing in addition linear free-energy relationships between the tautomerization constants $\left(K_{\mathrm{T}}\right)$ and the electronic effect of the substituents.
\end{abstract}

\section{Introduction}

Like straight-chain polyols (alditols), aminopolyols represent a versatile, yet underestimated subclass of carbohydrates, which share the physical properties of reducing sugars and enable facile glycoconjugation, although they overcome the limitations associated with the labile anomeric carbon. Some aminopolyols are naturallyoccurring substances, such as D-galactamine (1-amino-1-deoxy-Dgalactitol), isolated from Amaryllis belladonna, or D-mannosamine (1-amino-1-deoxy-D-mannitol), a minor metabolite of Streptomyces lavendulae, which produces the potent glycosidase inhibitor 1deoxy-nojirimycin, ${ }^{1,2}$ thus suggesting the role of D-mannosamine in the biosynthesis of the latter. The most known aminopolyol, 1amino-1-deoxy-D-ribitol, is present in flavin nucleotides (i.e. FMN and FAD), which serve as redox cofactors in cells. ${ }^{3}$ Other aminopolyols have been isolated in plant tumors induced by bacteria. ${ }^{4,5}$ As mentioned, the reactivity of sugar aminopolyols with carbonyl compounds has been scarcely explored. Our group reported the condensation of D-glucamine (1-amino-1-deoxy-D-glucitol, 1) ${ }^{6}$ and its $\mathrm{N}$-alkyl derivatives, ${ }^{7}$ as well as from $\mathrm{N}$-methyl-D-galactamine ${ }^{8}$ with benzaldehydes and substituted salicylaldehydes, from which both imines and 1,3-oxazolidines can be obtained. The corresponding reactions with acetophenones, which would afford desirable counterparts in the search for structural relationships, remain unknown. This study is aimed at bridging that gap, not only in terms of synthetic diversity, but also to investigate in detail the influence of

\footnotetext{
a. Departamento de Química Orgánica e Inorgánica, Facultad de Ciencias, and IACYS-Unidad de Química Verde y Desarrollo Sostenible, Universidad de Extremadura, E-06006 Badajoz, Spain E-mail: esthermc@unex.es (E.M.); palacios@unex.es (J.C.P.)

b. Department of Chemistry, Faculty of Natural and Environmental Sciences, The University of Southampton, Southampton SO17 1BJ, U.K.

† Electronic Supplementary Information (ESI) available: [General methods, crystallographic and spectroscopic data, and Cartesian coordinates for all optimized
} species.]. See DOI: 10.1039/x0xx00000x

electronic effects on tautomeric and configurational equilibria. On the other hand, some 2-hydroxyacetophenones, including glycoside derivatives, have been found in natural products, which add importance to further conjugation protocols. Thus, pestalothionol (2) is a recently discovered metabolite produced by the fungus Pestalotiopsis sp. PSU-ES194; ;a compound $\mathbf{3}$ can be isolated from the liquid culture of Ophiosphaerella herpotricha and acetophenone $\mathbf{4}$ from the bulbs of Dioscorea bulbifera. Some $O$-glucosides of polyhydroxyacetophenones include $\mathbf{5}$ from Artemisia stolonifera, $\mathbf{6}$ from Lawsonia inermis and 7 from Poligonum multiflorum. ${ }^{9 b}$ In context, it is likewise noteworthy the broad biological activity of other Schiff bases, often relying upon the imine-enamine tautomerism. ${ }^{10}$

\section{Results and discussion}

\section{Synthesis and structural characterization}

All synthetic transformations shown in Scheme 1 could easily be performed by adding equimolar amounts of D-glucamine (1) in water<smiles>CC(=O)c1c(C)cc(O)c(CC=C(C)C)c1O</smiles><smiles>CC(=O)c1c(O)cc(O)cc1CO</smiles><smiles>COc1c(O)cc(CCO)c(C(C)=O)c1O</smiles>

3<smiles>[Y]c1c(O)cc(O)c(C(C)=O)c1[Y]</smiles>

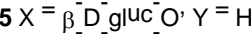
$6 X^{\prime}{ }^{-} D^{-}$gluc $O^{\prime} Y=\mathrm{OH}$ $7 \mathrm{X}=\mathrm{OH}^{\prime} \mathrm{Y}^{\prime}=\beta^{-} \mathrm{D}^{-} \mathrm{gluc}^{-} \mathrm{O}$ 


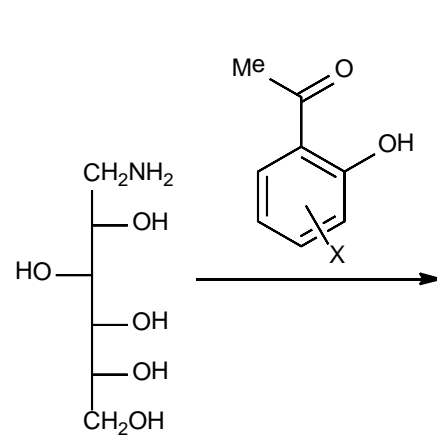

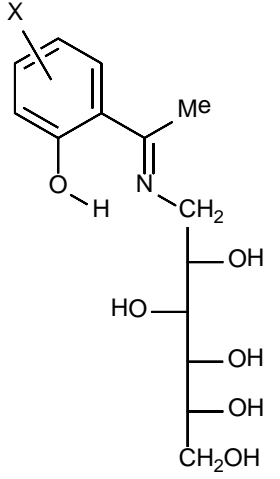

815

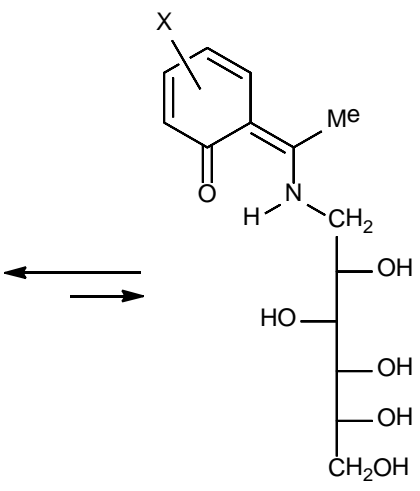

8, $16 X=$

9. $17 \mathrm{X}={ }^{-} \mathrm{Br}$

10. $18 X=5$ OMe

11. $19 \mathrm{X}=5^{\circ} \mathrm{C}$

12. $20 \mathrm{X}={ }^{-} \mathrm{NO}_{2}$

13, $21 \mathrm{X}=5 \mathrm{~F}$

14' $22 \mathrm{X}=3^{-} \mathrm{NO}_{2}, 5^{-} \mathrm{Br}$

15, $23 \mathrm{X}=4^{\prime} 5^{-}\left(\mathrm{OMe}_{2}\right.$

Scheme 1 Condensation of D-glucamine with diversely substituted 2-hydroxyacetophenones.

and the corresponding acetophenone in methanol. The mixture was heated for 20 minutes at $90^{\circ} \mathrm{C}$ leading to crystalline precipitates after slow cooling in variable, not optimized, yields (30-97\%). In most cases, further purification was carried out by recrystallization from ethanol. Our screening included acetophenones bearing both electron-donating and -withdrawing substituents.

The structures proposed for compounds 8-15 are consistent with their analytical and spectroscopic data. All had similar IR spectra showing the absorption of the hydroxyl groups at 3500-3200 $\mathrm{cm}^{-1}$, although the most diagnostic signal appears at 1627-1608 $\mathrm{cm}^{-1}$, corresponding to the stretching vibration of the $\mathrm{C}=\mathrm{N}$ bond, which lies at longer wavenumber than the absorptions for the aromatic nucleus and $\mathrm{C}-\mathrm{O}$ bonds. Schiff bases can exhibit different structures depending on whether they are in solution or in crystalline form. The low intensity of the signals at $1627-1608 \mathrm{~cm}^{-1}$ points to solid-state imine structures (8-15).

In solution NMR spectra allow a better discrimination between imine (8-15) and enamine (16-23) structures. The former shows a singlet proton signal at very low field ( 13-16 ppm), corresponding to the phenolic proton. In contrast, the enamine structure exhibits a multiplet signal ( 14-16 ppm) characteristic of the $\mathrm{NH}$ group. Because of such close shifts, the multiplicity constitutes the distinctive motif. Moreover, ${ }^{13} \mathrm{C}$ NMR spectra generally provide welldifferentiated resonances for the phenolic carbon of imines and the carbonyl of enamines ( $155 \mathrm{ppm}$ versus $\sim 180 \mathrm{ppm}) .{ }^{1} \mathrm{H}$ and ${ }^{13} \mathrm{C}$ NMR data of compounds 8-15 were quite similar. Unequivocal assignments were obtained through two-dimensional ${ }^{1} \mathrm{H}-{ }^{1} \mathrm{H}$ (COSY) and ${ }^{1} \mathrm{H}-{ }^{13} \mathrm{C}$ ( $\mathrm{HMQC}$ and $\mathrm{HMBC}$ ) correlations (Tables S3 and S4). Proton spectra showed a singlet signal in the range 17-15.8 ppm, in agreement with a phenolic proton; its high downfield resonance suggests a strong intramolecular hydrogen bridge. However, as we shall discuss below, the 5 -nitroderivative 12 had a ${ }^{13} \mathrm{C}$ NMR spectrum that deviated from those of the remaining imines.

All carbon resonances could be ascribed with confidence with the sole exception of the iminic carbon $(\mathrm{C}=\mathrm{N})$ and the phenolic carbon, both quaternary. Literature data for Schiff bases from acetophenones, ${ }^{11}$ indicate phenolic resonances in imines at $\sim 160$ ppm, whereas the iminic carbon appears at $\sim 172 \mathrm{ppm}$. Also, the aromatic C-OH signal of $\mathbf{2}$ is located at $160 \mathrm{ppm}^{.9 a}$ In fact, unlike 12, all Schiff bases show two quaternary carbon signals, one between 157 and 167 ppm, the other in the 171-176 ppm range. However, the resonances shown by the corresponding carbons of $\mathbf{1 2}, 178.4 \mathrm{ppm}$ and $176.1 \mathrm{ppm}$ are very similar, which raises the problem of a correct assignment. This could be achieved by both the HMBC spectrum (Fig. S23) and the carbon coupling pattern with the protons located in neighboring atoms in the coupled ${ }^{13} \mathrm{C}-\mathrm{NMR}$ spectrum (see ESI + ). This analysis evidences that the C-2 signal moves from $\sim 158-165 \mathrm{ppm}$ in 10, 13 and 14, otherwise consistent with the chemical shift of an aromatic carbon attached to the phenolic hydroxyl, to $\sim 178 \mathrm{ppm}$ in 12 , much closer to that of a carbonyl carbon. This variation in $\delta$ values reveals changes in the imine-enamine equilibrium, which favors a given tautomer depending on the electronic properties of the substituents.

As standard protocol in carbohydrate chemistry, $\mathrm{O}$-protection via acetylation often corroborates the structural assignment of unprotected derivatives and leads occasionally to new structural insights. As representative example we chose the acetylation of compound $\mathbf{9}$ with acetic anhydride in pyridine at room temperature, thus affording a crystalline material (24) from ethanol. Its IR spectrum shows absorptions at $1748 \mathrm{~cm}^{-1}$, assignable to the stretching vibration of the acetate carbonyls, and $1652 \mathrm{~cm}^{-1}$, likely stretching vibration of an amide carbonyl group, ${ }^{12}$ along with bands of C-O-C groups at $\sim 1380 \mathrm{~cm}^{-1}$ (phenolic acetate) and $\sim 1217 \mathrm{~cm}^{-1}$ (aliphatic acetate). The corresponding NMR spectra were recorded in various deuterated solvents (DMSO- $d_{6}, \mathrm{CDCl}_{3}$ and $\mathrm{C}_{6} \mathrm{D}_{6}$ ); the latter showing well-defined signal splitting (Figure 1).

To our surprise, NMR spectra regardless of the solvent employed, showed signal duplicity as if there were two acetylated products in a 1:1 ratio. However, after several recrystallizations, the proportion remained unchanged. The synthesis was reproducible and chromatographic analyses (t.l.c.) revealed the existence of only one product. These results led us to hypothesize the formation of a dimeric structure by acetylation.

As pointed out before, the unambiguous identification of all the protons were performed by 2D-COSY and HMQC spectra (Figures S37 and S38). Decoupled ${ }^{13} \mathrm{C}$ NMR/DEPT spectra also showed signal duplicity (chemical shifts of the most characteristic proton and carbon atoms are collected in Tables 1 and 2). 


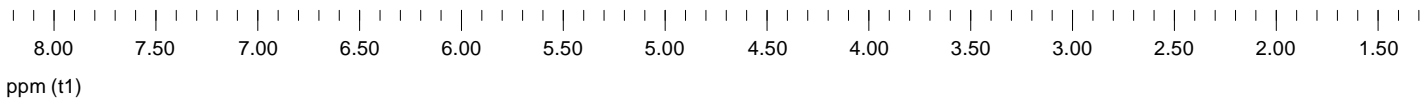

Fig. $1^{1} \mathrm{H}$ NMR spectrum of compound 24 recorded in $\mathrm{C}_{6} \mathrm{D}_{6}$ at $500 \mathrm{MHz}$.

Table 1 Proton chemical shifts of 24 in benzene- $d_{6}{ }^{\mathrm{a}}$

\begin{tabular}{ccccccccccc}
\hline Polyol chain $^{\mathrm{b}}$ & $\mathbf{H - 1}$ & $\mathbf{H - 1}$ & $\mathbf{H - 2}$ & $\mathbf{H - 3}$ & $\mathbf{H}-\mathbf{4}$ & $\mathbf{H}-\mathbf{5}$ & $\mathbf{H}-\mathbf{6}$ & $\mathbf{H}-\mathbf{6}^{\prime}$ & $\mathbf{C H}_{\mathbf{2}}$ & Compound $^{\mathrm{b}}$ \\
\hline $\mathbf{N}$ & 3.86 & 3.45 & 5.72 & 5.58 & 5.74 & 5.36 & 4.41 & 4.13 & $5.09,4.93$ & $\mathbf{2 8}$ \\
NAC & 3.28 & 3.15 & 4.17 & 5.44 & 5.51 & 5.30 & 4.29 & 4.22 & -- & $\mathbf{2 9}$ \\
\hline
\end{tabular}

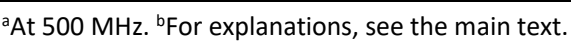

Table 2. Carbon chemical shifts of $\mathbf{2 4}$ in benzene- $d_{6}{ }^{\mathrm{a}}$

\begin{tabular}{ccccccccc}
\hline Polyol chain $^{\mathrm{b}}$ & C-1 & C-2 & C-3 & C-4 & C-5 & C-6 & CH $_{2}$ & Compound $^{\text {b }}$ \\
\hline N & 45.6 & 70.0 & 69.6 & $69.2^{c}$ & $69.0^{c}$ & 61.6 & 117.0 & $\mathbf{2 8}$ \\
NAc & 48.2 & 74.6 & $68.8^{c}$ & $69.0^{c}$ & 68.3 & 61.4 & -- & $\mathbf{2 9}$ \\
\hline
\end{tabular}

${ }^{\mathrm{a}}$ At $125 \mathrm{MHz}$. ${ }^{\mathrm{b}}$ For explanations, see the main text. 'Such chemical shift can be interchanged.

The two-dimensional correlation not only showed the presence of four $\mathrm{CH}_{2}$ groups, thereby accounting for two polyacetoxyl chains, but also the presence of an unexpected fifth $\mathrm{CH}_{2}$ group (Figure S45). Together with the analysis of chemical shifts and multiplicities, the formation of dimeric structure $\mathbf{2 4}$ seems to be reasonable enough, which shows the coexistence of one penta- $O$-acetyl-aminopolyol fragment along with an $\mathrm{N}$-acetyl-tetra- $\mathrm{O}$-acetyl-aminopolyol side chain (abbreviated in Tables 1 and 2 as $\mathrm{N}$ and NAc, respectively).

The main difference between the two fragments lies in the chemical shifts of the $\mathrm{H}-2$ and $\mathrm{C}-2$ signals. In fragment $\mathrm{N}$ the protons $\mathrm{H}-2$ to $\mathrm{H}-$ 5 are located in the 5.74-5.36 ppm range, with similar variations for the C-2 to C-5 atoms supporting individual acetate groups. However, the $\mathrm{H}-2$ proton in the NAc fragment shows a significant chemical shift variation relative to its counterpart in the other chain ( $\Delta \delta \sim 1.6 \mathrm{ppm}$ ). A large shielding like this points to the absence of the acetate group, i.e. C-2 bears a free hydroxyl group. Similar structural situations have been described previously. ${ }^{13}$ Furthermore, the ${ }^{1} \mathrm{H}$ NMR spectrum shows two singlets at $\sim 5.0 \mathrm{ppm}(\Delta \delta=0.16 \mathrm{ppm})$, which correspond to an olefinic group $\left(=\mathrm{CH}_{2}\right)$ at $\sim 117 \mathrm{ppm}$ (Fig. S45). The lack of coupling between both protons coincides with that described for $\mathrm{N}$ $\mathrm{C}(\mathrm{Ar})=\mathrm{CH}_{2}$ fragments. ${ }^{14}$ This would imply that acetylation had taken place through the tautomeric enamine form 25 , which adds to the $\mathrm{C}=\mathrm{N}$ bond of an acetylated imine molecule (26). The subsequent intramolecular migration of acetate at C-2, involving a fivemembered cyclic transition state would lead to the transient intermediate $\mathbf{2 7}$ (Scheme 2). This acetate migration likely occurs in the aqueous work-up prior to isolation, which prevents further acetylation of the hydroxyl group at C-2.

Said that, high-resolution mass spectrometry did not show any charge/mass relationship capable of evidencing the molecular ion of structure $\left.24\left[\mathrm{~m} / \mathrm{z}\left(\mathrm{M}+\mathrm{H}^{+}\right): 1258,1260,1262\right)\right]$; instead, the sum of

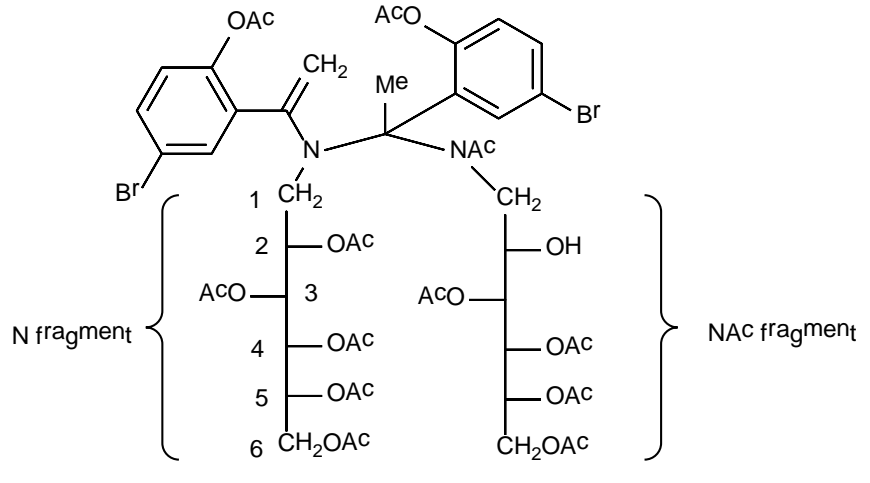

24

$\mathrm{m} / \mathrm{z} 672$ (or 674 ) and $m / z 630$ (or 632 ) found for the two most intense peaks does not correspond to the mass of $\mathbf{2 4}$. This conflict, however, could result from molecular-ion fragmentation of $\mathbf{2 4}$. When, before recording the mass spectrum, a solution of $\mathbf{2 4}$ was passed through an HPLC column, single peaks at $m / z \quad 672-674$ and $m / z \quad 630-632$ appeared. It is evident that either $\mathbf{2 4}$ dissociates into two molecules or it is actually a mixture of products. Fortunately, X-ray diffractometry came to rescue as crystals suitable for absolute determination were obtained by slow growth in ethanol. Results are shown in Figure $2 .{ }^{15}$

As strange as it may be, the crystallographic analysis shows the presence of two different peracetylated molecules in the unit cell, one with an open structure, enamine $\mathbf{2 8}$, plus a heterocycle derivative, oxazolidine 29. A view of that structural arrangement is depicted in ESIt, as the unit cell contains two molecules of $\mathbf{2 8}$ and two others of $\mathbf{2 9}$. Oxazolidine $\mathbf{2 9}$ has an S-stereochemistry at C-2 and both amide groups of $\mathbf{2 8}$ and $\mathbf{2 9}$ exhibit the $E$-configuration in the solid state. Lastly, it is worth pointing out the chiral homogeneity 
<smiles>C=C(NCC(OC(C)=O)C(OC(C)=O)C(OC(C)=O)C(C)OC(C)=O)C(OC(C)=O)C(OC(C)=O)C(OC(C)=O)C(CN=C(C)c1cc(Br)ccc1OC(C)=O)OC(C)=O</smiles>

25
26

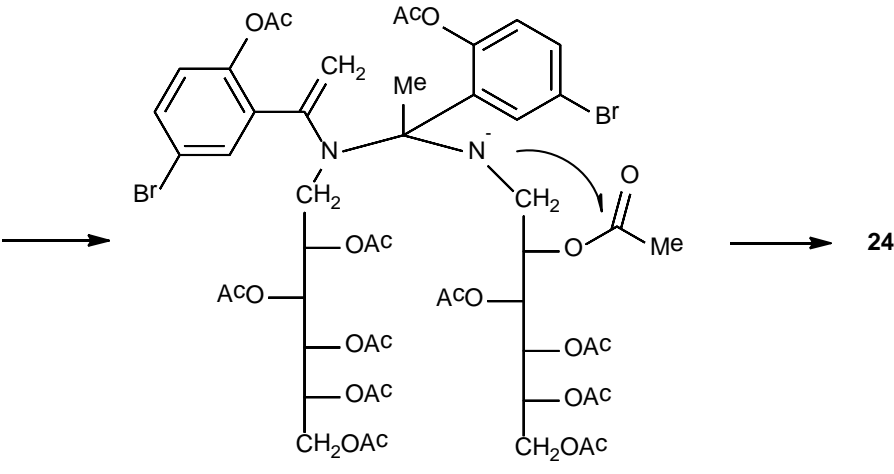

27

Scheme 2 Proposed dimerization of $\mathbf{2 6}$ by acetylation in basic medium.

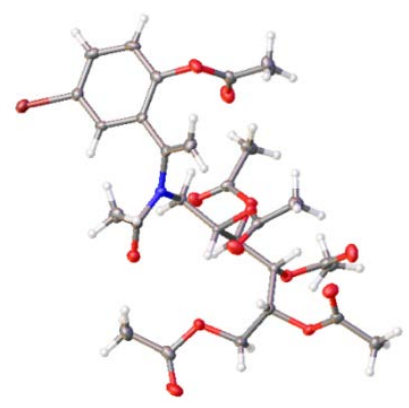

28

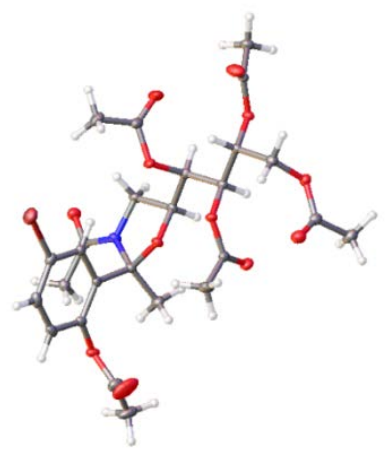

29
Fig. 2 X-ray diffraction structures of compounds $\mathbf{2 8}$ and 29. Ellipsoids are drawn at $50 \%$ probability

of the sample, without involving configurational inversion or racemization, as inferred from the Flack parameter (see ESI + ).

The unexpected result explains why experiments were unable to solve the puzzle on the wrong structure $\mathbf{2 4}$. Compounds $\mathbf{2 8}$ and $\mathbf{2 9}$ crystallize together with a 1:1 stoichiometry in the unit cell; and as a result the 1:1 ratio of the signals in NMR spectra remained unaffected, despite the fact that several crystallizations were carried out. The involvement of oxygen at $\mathrm{C}-2$ in the formation of the oxazolidine ring also justifies the chemical shift observed for $\mathrm{H}-2$. Assignments to structures $\mathbf{2 8}$ and $\mathbf{2 9}$ of the chemical shifts of protons and carbons, collected in Tables 3 and 4, are indicated in the last column. In order to make this comparison easier, the same proton numbering has been maintained for both fragments; however, they are listed with the correct nomenclature in the Experimental section. It is now evident that the shift difference between $\mathrm{H}-4$ and $\mathrm{H}-4$ ' in $\mathbf{2 9}$, less than $0.5 \mathrm{ppm}\left(\Delta \delta_{\mathrm{H}-4}=3.28-3.15=0.13 \mathrm{ppm}\right)$, agrees with the absolute $\mathrm{S}$-configuration informed by $\mathrm{X}$-ray diffraction. Moreover, this result validates the correct assignment of the stereochemistry, carried out through the values of $\Delta \delta_{\mathrm{H}-4}$, to a series of oxazolidines obtained from $\mathrm{D}$-glucamine ${ }^{6}$ and of $\mathrm{N}$-methyl-D-glucamine $\mathrm{e}^{7,8}$ by reaction with aromatic aldehydes.

In addition, this reactivity pattern could be observed in other imines and thus, the acetylation of $\mathbf{1 1}$ led to the same results as $\mathbf{9}$, yielding a mixture of $\mathbf{3 0}$ and $\mathbf{3 1}$. Likewise, imine $\mathbf{1 0}$ afforded $\mathbf{3 3}$ mainly, which was the isolated product.

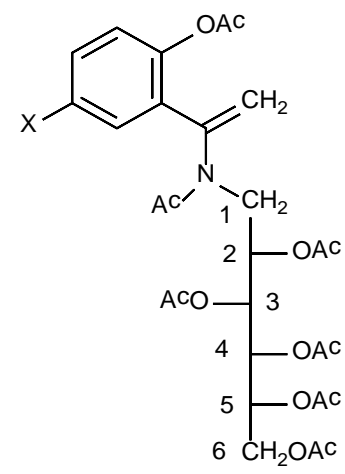

$28 \mathrm{X}=\mathrm{Br}^{\mathrm{r}}$

$30 \mathrm{X}=\mathrm{Cl}$ $32 x=$ OMe

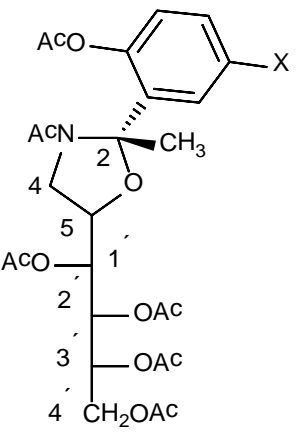

$29 \mathrm{X}={ }_{\mathrm{Br}}$

$31 \mathrm{X}=\mathrm{Cl}$

$33 x=$ ome

The crystallographic behavior of $\mathbf{2 8}$ and $\mathbf{2 9}$ is very unusual; it seems that one molecule of each compound forms a dimer and it joins others to form the crystal. We performed theoretical DFT calculations ${ }^{16}$ at the M06-2X/6-311G(d,p), ${ }^{17,18}$ using the Gaussian09 package, ${ }^{19}$ in order to ascertain whether the formation of dimers composed of $\mathbf{2 8}$ and $\mathbf{2 9}$ is favored by some type of interaction between them. The geometric parameters (distances and bond angles) determined by X-ray diffraction analysis were employed. The energy in the gas phase of both molecules has been calculated separately and its sum then compared with that of dimer formation at identical distance and arrangement as found in the unit cell (Table 3). The dimer is slightly less stable than the two molecules separately, and therefore the packing of dimeric units in the lattice should largely be responsible for crystal's stability.

Table 3 Electronic and Gibbs energies for compounds $\mathbf{2 8}$ and $\mathbf{2 9}^{\mathrm{a}}$

\begin{tabular}{ccccc} 
& $\mathrm{E}$ & $\mathrm{G}$ & $\Delta \mathrm{E}$ & $\Delta \mathrm{G}$ \\
\hline $\mathbf{2 8}$ & -2945406.02 & -2945060.06 & & \\
$\mathbf{2 9}$ & -2849646.52 & -2849317.6 & & \\
$\mathbf{2 8 + 2 9 ^ { \mathrm { b } }}$ & -5795052.54 & -5794377.66 & 0.00 & 0.00 \\
Dimer 28/29c & -5795052.62 & -5794362.96 & -0.08 & 1.34 \\
\hline
\end{tabular}

${ }^{a} \mathrm{M06}-2 \mathrm{X} / 6-311 \mathrm{G}(\mathrm{d}, \mathrm{p})$, in $\mathrm{kcal} \mathrm{mol}^{-1}$. bS ${ }^{\mathrm{S}} \mathrm{m}$ of 28 and 29 calculated separately. ${ }^{\mathrm{C}} \mathrm{Calculation}$ of the dimer as arranged in the unit cell. 


\section{Rotational equilibrium}

Variable-temperature ${ }^{1} \mathrm{H}$ NMR experiments for the mixture of compounds $\mathbf{2 8}$ and $\mathbf{2 9}$ conducted in $\mathrm{CDCl}_{3}$ show the appearance of sharp signals at low temperature, which coalesce as temperature increases giving rise to simplified spectra (Figure 3). The origin of this behavior should clearly be ascribed to restricted rotation of the amide bond of $\mathbf{2 9}$ at room temperature, ${ }^{6}$ leading to equilibration between $E$ and $Z$ rotamers (Scheme 3 ). The integration of signals at $250 \mathrm{~K}$ enables an estimation of rotamer population $(77 \%$ of the major one).

The analysis of NMR data gives also indication on the stereochemistry around the amide bond. We have previously reported that for other $\mathrm{N}$-acetyloxazolidines in solution, the $\mathrm{E}$ rotamer shows a very shielded signal for the methyl protons of the amide group $\left(\delta_{\text {MecoN }} \sim 1.8 \mathrm{ppm}\right.$ ). This shielding effect has its origin in the spatial disposition of that methyl group, which lies in the vicinity of the aromatic ring. ${ }^{6}$ Obviously, this effect cannot occur in the $Z$ rotamer, for which the methyl group is kept away from the aromatic moiety. For compound 29, proton NMR spectra recorded in different solvents $\left(\mathrm{C}_{6} \mathrm{D}_{6}, \mathrm{DMSO}-\mathrm{d}_{6}\right.$ and $\left.\mathrm{CDCl} \mathrm{C}_{3}\right)$, show a highly shielded acetate signal ( $\delta 1.65 \mathrm{ppm}, 1.93 \mathrm{ppm}$ and $1.83 \mathrm{ppm}$, respectively), consistent with the $E$-rotamer.<smiles>[R]C1CN(C(C)=O)C([AlH2])([AlH2])O1</smiles>

E

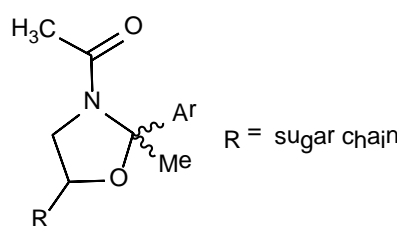

Scheme $3 E$ and $Z$ rotamers for $N$-acetyloxazolidines derived from polyacetylated $D$-glucamine.
We have calculated the relative energies of both rotamers in the gas phase as well as in $\mathrm{CHCl}_{3}$ (bulk solvation using the SMD method), ${ }^{20}$ whose results are gathered in Table 3 and Figure 4 . The calculation shows that the most stable rotamer has $Z$ configuration, regardless of the medium, although the energy difference drops significantly when solvation is taken into account. As pointed out earlier, the $E$ rotamer however populates the solid state as this configuration gives rise to a more favorable crystal packing.

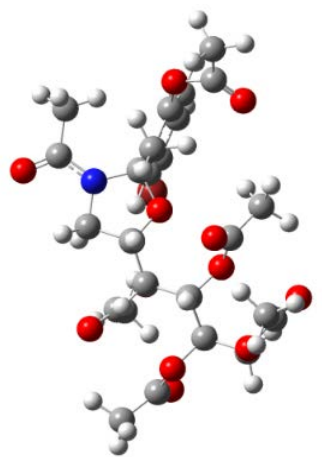

$29 E$

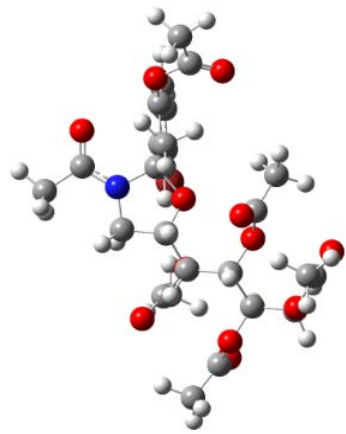

$29 Z$
Fig. 4 Optimized structures of $E$ and $Z$ rotamers of 29.

Table 3 Relative electronic and Gibbs energies for $E$ and $Z$ rotamers of $\mathbf{2 9}^{\circ}$

\begin{tabular}{ccccc} 
& \multicolumn{2}{c}{ Gas phase } & \multicolumn{2}{c}{$\mathrm{CHCl}_{3}$} \\
\cline { 2 - 5 } & $\Delta \mathrm{E}$ & $\Delta \mathrm{G}$ & $\Delta \mathrm{E}$ & $\Delta \mathrm{G}$ \\
\hline $29 E$ & 1.51 & 2.17 & 0.75 & 0.78 \\
$29 Z$ & 0.00 & 0.00 & 0.00 & 0.00 \\
\hline
\end{tabular}

${ }^{\mathrm{a}}$ At the M06-2X/6-311G(d,p) level, in $\mathrm{kcal}^{\mathrm{mol}}{ }^{-1}$.

3336

2opk

$250 \mathrm{~K}$

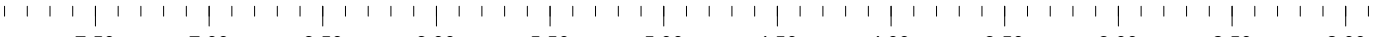

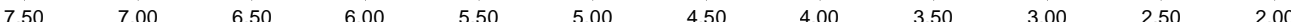

ppm (t1)

Fig. 3 Variable-temperature ${ }^{1} \mathrm{H}$ NMR spectra recorded for a mixture of 28 and 29 in $\mathrm{CDCl}_{3}$. 
The calculated energy difference allows us to estimate the equilibrium constant for the interconversion of rotamers in $\mathrm{CHCl}_{3}$ at $250 \mathrm{~K}$, according to eq. [1]:

$$
K_{\text {rot }}=\frac{[E]}{[Z]}=e^{-\frac{\Delta G}{R T}}=e^{-\frac{780}{1.987 \cdot 250}}=0.21
$$

From that equilibrium constant, the theoretical population of rotamers can easily be obtained, assuming that $[E]+[Z]=1$ (eq. [2]):

$$
[\mathrm{Z}](\%)=\left[\frac{1}{\left(1+K_{\text {rot }}\right)}\right] \cdot 100=\left[\frac{1}{(1+0.21)}\right] \cdot 100=82.8 \%
$$

These results constitute an accurate prediction of experimental data, as the major rotamer, obtained by peak integration in the ${ }^{1} \mathrm{H}$ NMR spectrum at $250 \mathrm{~K}$, amounts to $77 \%$ (Figure 3 ).

\section{Configurational stability of Schiff bases}

Although, with the exception 12, all Schiff bases show an imine form in the solid state, rapid equilibration with the enamine tautomer occurs in solution. Yet, NMR data agree with the preferential formation of the former (Scheme 4).

In order to assess this tautomeric equilibrium in detail, further DFT calculations were carried out. Initially, this proved to be problematic as we were unable to locate the relative minima for enamine structures using the M06-2X functional; all calculations ended up invariably in the imine tautomers. We moved then to the alternative B3LYP/6-311G(d,p) combination. ${ }^{21}$ Table 4 shows the relative energies in the gas phase of both structures, as well as those of the corresponding transition states $\left(\mathrm{ET}^{\ddagger}\right)$, for compounds 8-10 and $\mathbf{1 2}$. Imaginary vibration frequencies (in $\mathrm{cm}^{-1}$ ) for saddle points have also been collected, whose main component is supplied by the $\mathrm{O}-\mathrm{H}$ stretching, as otherwise expected for such proton transfer reactions.

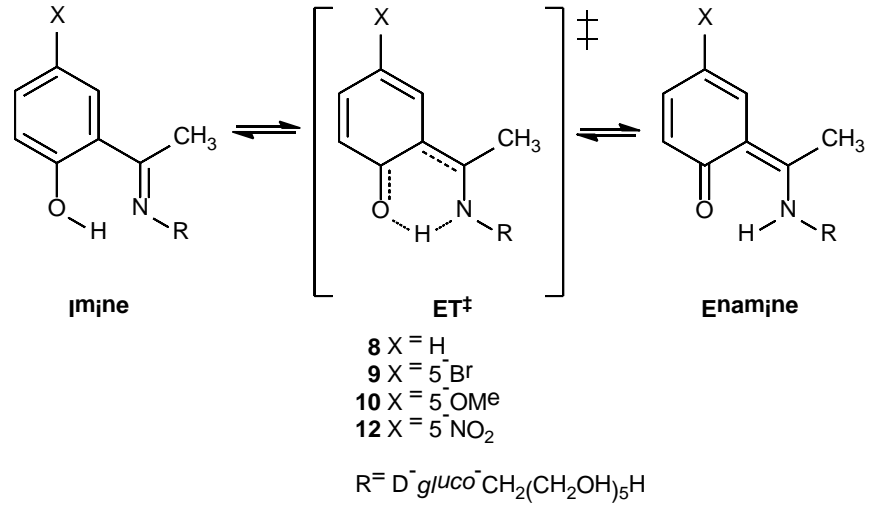

Scheme 4 Equilibrium between imine and enamine tautomers of Dglucamine acetophenones.
In the gas phase, the imine tautomer is more stable than the enamine form, irrespective of the substitution pattern at the aromatic ring. The energy difference, however, decreases when electronwithdrawing groups are present, as exemplified by compound $\mathbf{1 2}$. Solvent effects are clearly visible by calculating the relative stabilities of both species in DMSO (Table 4) using the SMD method as well. ${ }^{20}$ Solvation causes a further decrease in energy differences between imine and enamine tautomers, and the latter becomes prevalent for compound $\mathbf{1 2}$ in full agreement with the experimental data.

The interconversion barriers involving imine and enamine structures, determined in the gas phase, are sufficiently low $\left(\Delta \mathrm{G}^{\ddagger}<2.1 \mathrm{kcal} \mathrm{mol}^{-}\right.$ $\left.{ }^{1}\right)$, so that tautomeric interconversion proceeds easily and fast at room temperature. As mentioned above, in DMSO these energy barriers are smaller $\left(\Delta \mathrm{G}^{\ddagger}<0.5 \mathrm{kcal} \mathrm{mol}^{-1}\right)$ and even negative. In fact, the Gibbs free energy for the transition state is slightly lower than that found for the enamine structure. Thus, the most significant feature of this equilibrium is that the activation energies in the endothermic direction, i.e. going from enamine to imine tautomers for 8-10 and from imine to enamine tautomers for $\mathbf{1 2}$ (in DMSO), are always negative $\left(\Delta G^{\ddagger} \leq 0.0 \mathrm{kcal} \mathrm{mol}^{-1}\right)$. Figure 4 shows schematic diagrams of electronic and Gibbs energies for the intramolecular hydrogen transfer between these tautomers based on the calculated values.

The computational analysis indicates that the activation energy for the imine-to-enamine transformation is positive $\left(\Delta \mathrm{G}_{\mathrm{i}}^{\ddagger}=\Delta \mathrm{G}_{\mathrm{Ts}}{ }^{\ddagger}\right.$ $\left.\Delta \mathrm{G}_{\text {imine }} \geq 0.0 \mathrm{kcal} \mathrm{mol}^{-1}\right)$. In stark contrast, the activation energy is negative for the opposite enamine-to-imine tautomerization (-1.4 $\leq$ $\Delta \mathrm{G}_{\mathrm{e}}^{\ddagger}=\Delta \mathrm{G}_{\mathrm{Ts}}{ }^{\ddagger}-\Delta \mathrm{G}_{\text {enamine }}<0.0 \mathrm{kcal} \mathrm{mol}^{-1}$ ).

The tautomerization of 8-15 in $\mathbf{1 6 - 2 3}$ are characterized not only by low energy barriers $\left(<2.1 \mathrm{kcal} \mathrm{mol}^{-1}\right)$, but also by high imaginary frequencies at the saddle point of the potential energy surface (PES) (-1100 to $-875 \mathrm{~cm}^{-1}$, see Table 4). These high frequencies cause a sharp drop of the zero-point energy (ZPE). As a result, and taken together the electronic energy of the thermal corrections and ZPE, there is a marked decrease in the internal energy as well as in the enthalpy and free energy at the saddle point. This generates a variational effect that leads to negative values for both $\Delta \mathrm{H}^{\ddagger}$ and $\Delta \mathrm{G}^{\ddagger}$, thereby shifting their maxima with respect to the saddle point. ${ }^{22}$ Negative values of the energy barrier $\left(\Delta \mathrm{H}^{\ddagger}\right.$ and $\left.\Delta \mathrm{G}^{\ddagger}\right)$ have been described in other proton transfers of intramolecular $\mathrm{H}$-bonded systems, ${ }^{23}$ substituted malondialdehydes ${ }^{22}$ and their mono- and diaza derivatives (aminoacroleins and vinamidines, respectively) ${ }^{24}$ and heterocyclic hydrazones of gossypol. ${ }^{25}$ Other authors, however, have cautioned about the accuracy of DFT methods to predict the most stable structure of tautomeric equilibria in view of the small energy differences, within the inherent errors of some hybrid functionals. ${ }^{26}$

\begin{tabular}{|c|c|c|c|c|c|c|c|c|c|c|c|c|c|c|}
\hline \multirow[b]{3}{*}{ Compound } & \multicolumn{7}{|c|}{ Gas Phase } & \multicolumn{7}{|c|}{ DMSO $^{b}$} \\
\hline & \multicolumn{2}{|c|}{ Imine } & \multicolumn{3}{|c|}{$\mathrm{ET}^{\ddagger}$} & \multicolumn{2}{|c|}{ Enamine } & \multicolumn{2}{|c|}{ Imine } & \multicolumn{3}{|c|}{$\mathrm{ET}^{\ddagger}$} & \multicolumn{2}{|c|}{ Enamine } \\
\hline & $\Delta \mathrm{E}$ & $\Delta \mathbf{G}$ & $\Delta \mathrm{E}^{\ddagger}$ & $\Delta \mathbf{G}^{\ddagger}$ & $\tilde{\mathbf{v}}^{\ddagger c}$ & $\Delta \mathrm{E}$ & $\Delta \mathbf{G}$ & $\Delta \mathrm{E}$ & $\Delta \mathbf{G}$ & $\Delta \mathrm{E}^{\ddagger}$ & $\Delta \mathbf{G}^{\ddagger}$ & $\tilde{\mathbf{v}}^{ \pm c}$ & $\Delta \mathrm{E}$ & $\Delta \mathbf{G}$ \\
\hline 8 & 0.00 & 0.00 & 4.47 & 2.03 & -874.5 & 3.99 & 3.40 & 0.00 & 0.00 & 2.80 & 0.08 & -1095.7 & 1.04 & 1.05 \\
\hline 9 & 0.00 & 0.00 & 4.18 & 1.53 & -932.8 & 3.54 & 2.79 & 0.00 & 0.00 & 2.55 & -0.08 & -1108.9 & 0.57 & 1.05 \\
\hline 10 & 0.00 & 0.00 & 4.52 & 2.08 & -964.2 & 3.79 & 3.22 & 0.00 & 0.00 & 3.17 & 0.46 & -1105.6 & 2.71 & 1.26 \\
\hline 12 & 0.00 & 0.00 & 3.03 & 0.33 & -1014.8 & 1.94 & 1.74 & 0.00 & 0.00 & 1.25 & -0.21 & -1077.0 & -1.98 & -0.66 \\
\hline
\end{tabular}

Table 4 Relative electronic and Gibbs energies ${ }^{\mathrm{a}}$

${ }^{a} A t$ the $B 3 L Y P / 6-311 G(d, p)$ level in $\mathrm{kcal} \mathrm{mol}^{-1}{ }^{\mathrm{b}}\left(\mathrm{SMD}\right.$ method). ${ }^{\mathrm{c}} \mathrm{ln} \mathrm{cm}^{-1}$. 

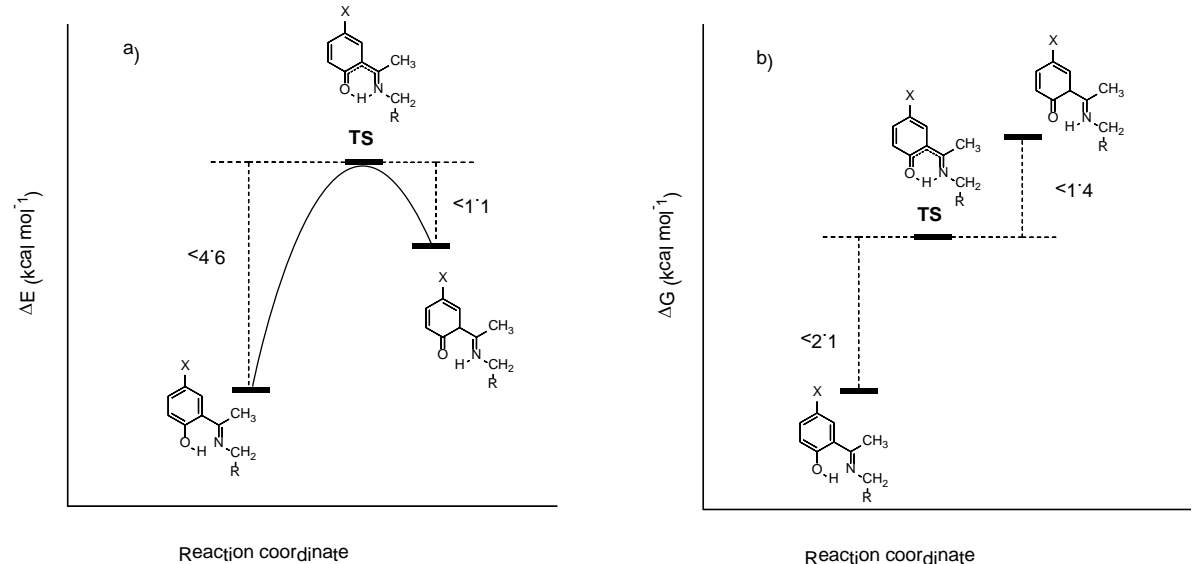

Fig. 4 Schematic diagrams showing the electronic energy (a) and Gibbs energy (b) relative to the interconversion between imine and enamime tautomers in the gas phase.

\section{Hydrogen bonding energy}

The largest downfield shift observed for the phenolic proton ( $16-17$ $\mathrm{ppm}$ ) is consistent with a strong intramolecular hydrogen bond. The strength of this hydrogen bond $\left(E_{\mathrm{HB}}\right.$ in $\left.\mathrm{kcal} \mathrm{mol}^{-1}\right)$ can be estimated empirically using the Schaefer correlation, ${ }^{27} \Delta \delta=(-0.4 \pm 0.2)-E_{\mathrm{HB}}$, where $\Delta \delta$ (in ppm) measures the difference between the chemical shifts of the O-H signal $\left(\delta_{\text {exp }}\right)$ in 8-15 and phenol $(\delta 4.29)$. Since $\Delta \delta=$ $\delta_{\exp }-4.29$, the resulting eq. [3] is obtained:

$$
\mathrm{E}_{\mathrm{HB}}=-\delta_{\exp }+3.89 \pm 0.2
$$

The hydrogen bond energies determined for 8-15 lie within -12 and $13 \mathrm{kcal} \mathrm{mol}^{-1}$ in DMSO. These values correspond to strong hydrogen bonds according to well-established classifications (strength for a weak hydrogen bond, $-4 \mathrm{kcal} \mathrm{mol}^{-1}$; for a strong, -4 to $-15 \mathrm{kcal} \mathrm{mol}^{-1}$ and for a very strong, -15 to $\left.-40 \mathrm{kcal} \mathrm{mol}^{-1}\right) .{ }^{28}$ Kleinpeter et al. ${ }^{29}$ have shown that ring current effects on resonance-assisted and intramolecularly bridged hydrogen bond protons contribute considerably to the chemical shift of the latter making it questionable to use $\delta(\mathrm{OH}) / \mathrm{ppm}$ in the estimation of intramolecular hydrogen bond strength. But they conclude that in simple compounds such as salicylaldehyde the effect is much smaller than -1 ppm deshielding, whereas only in polycyclic aromatic systems these effects can be up to $2 \mathrm{ppm}$ deshielding. Therefore, the error in the estimate obtained is less than $1 \mathrm{kcal} \mathrm{mol}^{-1}$ and barely alters the calculated magnitude of the $\mathrm{H}$-bridge strength.

However, the strength can also be inferred from computation, though this methodology can only be applied to the imine structures. On the other hand, the strength of other hydrogen bonds, which involve the phenol group and nitrogen with the hydroxyl groups of the sugar side chain, can also be determined. The calculated energies for the structures involving phenolic hydrogen bonds of $\mathbf{8 , 1 0}$ and $\mathbf{1 2}$ and the corresponding ones without $\mathrm{H}$-bonding (34-36), in which the phenolic bond has been rotated $180^{\circ}\left(\theta_{\mathrm{H}-\mathrm{O}-\mathrm{C2}-\mathrm{Cl} 1}\right)$, have been taken into account for comparison.

Intramolecular hydrogen bridges between the nitrogen atom with either the first or second $\mathrm{OH}$ groups of the saccharide chain lead to five- membered (37-39) and six-membered (40-43) rings, respectively. Moreover, in the course of such calculations, $\mathrm{H}$-bonded structures involving more than one hydroxyl group of the sugar chain were also disclosed (43-45). Such results are compiled in Table 5 and optimized structures for $\mathbf{8}, \mathbf{3 4}, \mathbf{3 7}, \mathbf{4 0}$, and $\mathbf{4 3}$ are shown in Figure 5 .<smiles>[X]c1ccc(Oc2ccccc2C(C)=NCC(O)C(O)C(O)C(O)CO)c(O)c1</smiles><smiles>[X]c1ccc(O)c(C(C)=NCC(O)C(O)C(O)C(O)CO)c1</smiles>

$$
\begin{aligned}
8 \mathrm{X} & =\mathrm{H} \\
10 \mathrm{x} & =5 \mathrm{-OMe} \\
12 \mathrm{X} & =5 \mathrm{NO}_{2}
\end{aligned}
$$<smiles>[X]c1ccc(O)c(C(C)=NC[C@@H](O[TlH])[C@H](O)[C@H](O)[C@H](O)[C@H](C)O)c1</smiles>

$37 \mathrm{X}=\mathrm{H}$

$38 \mathrm{X}=5 \mathrm{OMe}$

$39 \mathrm{x}={ }^{-} \mathrm{NO}_{2}$<smiles>[X]c1ccccc1C(C)=NC[C@H](O)[C@@H](O[2H])[C@H](O)[C@H](O)CO</smiles>

$40 \mathrm{X}=\mathrm{H}$

$41 \mathrm{X}=5 \mathrm{OMe}$

$42 \mathrm{X}={ }^{5} \mathrm{NO}_{2}$

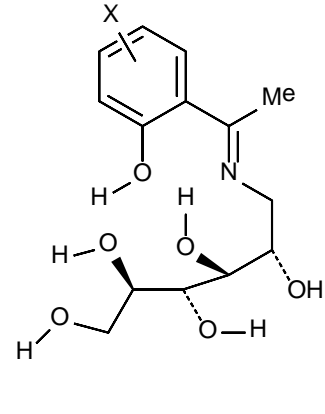

$43 \mathrm{X}=\mathrm{H}$

$44 \mathrm{X}=5 \mathrm{OMe}$

$45 \mathrm{X}=5 \mathrm{NO}_{2}$ 
Table 5 Relative electronic and Gibbs energies for compounds 8, 10, 12, and 34-45

\begin{tabular}{|c|c|c|c|c|c|c|c|c|c|c|c|c|c|c|c|}
\hline & 8 & 34 & 37 & 40 & 43 & 10 & 35 & 38 & 41 & 44 & 12 & 36 & 39 & 42 & 45 \\
\hline$\Delta \mathrm{E}^{\mathrm{a}, \mathrm{c}}$ & 0.00 & 14.09 & 14.45 & 11.03 & 10.93 & 0.00 & 13.79 & 14.06 & 10.60 & 9.87 & 0.00 & 15.17 & 15.96 & 13.02 & 12.47 \\
\hline$\Delta \mathbf{G}^{\mathrm{a}, \mathrm{c}}$ & 0.00 & 12.68 & 12.50 & 9.98 & 12.43 & 0.00 & 12.02 & 11.89 & 9.40 & 11.25 & 0.00 & 13.49 & 14.11 & 12.43 & 13.91 \\
\hline$\Delta \mathrm{E}^{\mathrm{a}, \mathrm{d}}$ & 0.00 & 12.55 & 12.13 & 8.65 & 11.91 & 0.00 & 12.24 & 11.80 & 8.31 & 10.92 & 0.00 & 13.23 & 13.19 & 9.89 & 13.47 \\
\hline$\Delta \mathbf{G}^{\mathrm{a}, \mathrm{d}}$ & 0.00 & 10.70 & 10.61 & 7.67 & 13.18 & 0.00 & 10.33 & 9.41 & 6.78 & 12.26 & 0.00 & 12.72 & 12.56 & 10.62 & 15.16 \\
\hline$\Delta \mathrm{E}^{\mathrm{b}, \mathrm{c}}$ & 0.00 & 13.48 & 13.39 & 9.13 & 5.93 & 0.00 & 13.23 & 12.94 & 8.67 & 4.70 & 0.00 & 14.45 & 14.92 & 11.19 & 7.52 \\
\hline$\Delta G^{b, c}$ & 0.00 & 12.70 & 12.09 & 8.62 & 8.07 & 0.00 & 11.82 & 12.38 & 9.03 & 6.17 & 0.00 & 13.11 & 12.91 & 10.21 & 8.91 \\
\hline$\Delta \mathrm{E}^{\mathrm{b}, \mathrm{d}}$ & 0.00 & 11.37 & 10.99 & 6.72 & 7.16 & 0.00 & 10.81 & 10.64 & 6.34 & 6.11 & 0.00 & 11.85 & 12.03 & 7.96 & 8.69 \\
\hline$\Delta G^{b, d}$ & 0.00 & 10.70 & 9.84 & 6.30 & 8.98 & 0.00 & 10.49 & 9.21 & 6.01 & 8.34 & 0.00 & 11.06 & 10.50 & 8.03 & 9.97 \\
\hline
\end{tabular}

${ }^{a}$ At the B3LYP/6-311G(d,p) level. ${ }^{b}$ At the M06-2X/6-311G(d,p) level. In the gas phase. ${ }^{d}$ Including the solvent effect (SMD model, DMSO as solvent)

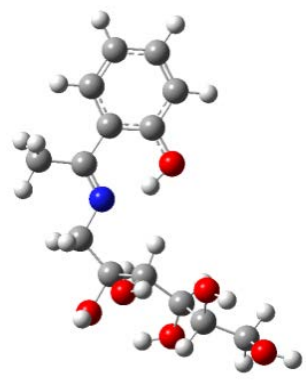

8

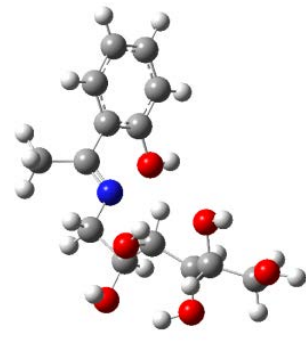

34

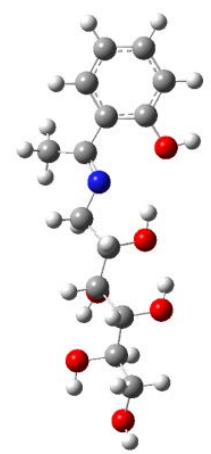

37

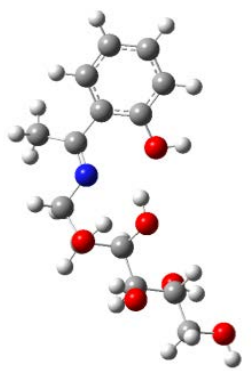

40

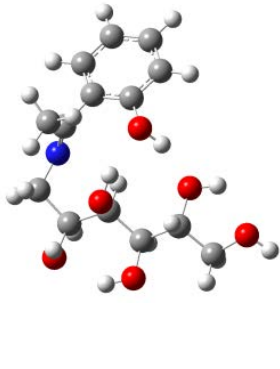

43

Fig. 5 Optimized structures of $8,34,37,40$, and 43

In the gas phase, the calculated strength of $\mathrm{H}$-bonding in structures $\mathbf{8}, \mathbf{1 0}$, and 12 lies in the range $12-13.5 \mathrm{kcal} \mathrm{mol}^{-1}$. Solvation in DMSO causes a little decrease, up to $10-12 \mathrm{kcal} \mathrm{mol}^{-1}$ (SMD model), in agreement with that determined by Equation [3]. It is noteworthy that the lowest values are reached with electron-releasing groups at the aromatic ring and the highest ones with electron-withdrawing substituents. Structures 37-39 are appreciably less stable than 8, 10, and 12 , in the range $9-10.5 \mathrm{kcal} \mathrm{mol}^{-1}$ at DMSO, and by $6-8 \mathrm{kcal} \mathrm{mol}^{-1}$ for 40-42. Finally, structures 43-45 in which the hydroxyl of the chain also forms hydrogen bonds with the phenolic hydroxyl, are less stable, by $8-10 \mathrm{kcal} \mathrm{mol}^{-1}$, than $\mathbf{8}, \mathbf{1 0}$, and $\mathbf{1 2}$ (DMSO). It can be concluded that the intramolecular hydrogen bridge involving the phenolic group and the iminic nitrogen is by far the most stable interaction.

This protocol is not applicable to the $\mathrm{NH}$... $\mathrm{O}$ hydrogen bond of enamines 16-18 and 20. For all tautomers, however, the hydrogen bonding energy $\left(E_{\mathrm{HB}}\right.$ in $\left.\mathrm{kcal} \mathrm{mol}^{-1}\right)$ can be quantified through an empirical relationship (eq. [4]), ${ }^{30}$ developed for intramolecular hydrogen bonds in enol-aldehydes and enol-imines derived from malonaldehyde and salicylaldehyde, expressed as:

$$
E_{H B}\left(\mathrm{kcal} \mathrm{mol}^{-1}\right)=-5.554 * 10^{5} e^{-4.12 d_{D \cdots A}}
$$

where $d_{D \cdots A}$ denotes either an experimentally measured or theoretically calculated distance (in $\AA$ ) between donor (D) and acceptor (A) atoms involved in the non-covalent interaction. Table S5 lists geometric data and strength of the hydrogen bonds for tautomers 8-10, 12, 16-18 and 20. The apparent hydrogen bond energy, $E_{\mathrm{HB}} \sim 14-18 \mathrm{kcal} \mathrm{mol}^{-1}$ (gas phase) and $\sim 14-17 \mathrm{kcal} \mathrm{mol}^{-1}$ (in DMSO), is a bit higher than that of previous calculations.

\section{Electronic effects of substituents}

It is fair to say that the effect of substituents on the chemical shift of the imine hydrogen and carbon atoms has been evaluated for structurally simple imines. ${ }^{31}$ It is surprising nevertheless, that little or no studies address the substituent effect on imine-enamine equilibria from a quantitative standpoint. In the present study, the new Schiff bases derived from 2-hydroxyacetophenones are characterized by a strong intramolecular hydrogen bond ( $10-20 \mathrm{kcal}$ $\left.\mathrm{mol}^{-1}\right) .{ }^{32}$ The position occupied by the hydrogen atom, covalently bound to oxygen in the phenol-imine or to the nitrogen atom in the keto-enamine structure, obviously depends on the relative basicity of both atoms; as hydrogen will bind to the most basic center. In this context, proton transfer can be intuitively interpreted as an intramolecular acid-base reaction. ${ }^{33}$ Both basic centers are also connected by a small molecular fragment or $\pi$-conjugated spacer; it is an unsaturation belonging to an aromatic ring, giving rise to a kind of special tautomeric system usually called hydrogen bridge assisted by resonance. ${ }^{32}$ It is pertinent to evaluate how the electronic 
character of the substituents affects the oxygen and nitrogen atoms involved in the tautomeric equilibrium. This basicity in turn depends on the electron density of each atom, which is reflected by the chemical shifts of the proton and nitrogen atom as well as the iminic and phenolic carbons. Scheme 5 envisages the multiple equilibria associated to the phenolimine-ketoenamine tautomerism in 2hydroxyacetophenones. 34

For such equilibria, eq. [5] can be deduced (see ESI + ): ${ }^{34}$

$$
\log K_{\mathrm{T}}=\rho\left(\sigma_{\mathrm{x}}^{\mathrm{OH}}-\sigma_{\mathrm{x}}^{\mathrm{NH}}\right)+\mathrm{c}=\rho \sigma_{\mathrm{ef}}+\mathrm{c}
$$

where the difference $\sigma_{\mathrm{ef}}=\sigma_{\mathrm{x}}^{\mathrm{OH}}-\sigma_{\mathrm{x}}^{\mathrm{NH}}$, represents the net or effective effect that the delocalized cyclic tautomeric system exerts on substituent $X$. For substituents at position $\mathrm{C}-5, \sigma_{\mathrm{x}}^{\mathrm{OH}}=$ $\sigma_{\text {para }}^{\mathrm{x}}$ while at position $\mathrm{C}-4, \sigma_{\mathrm{x}}^{\mathrm{OH}}=\sigma_{\text {meta }}^{\mathrm{x}}$. Analogously, for substituents at position $\mathrm{C}-4, \sigma_{\mathrm{X}}^{\mathrm{NH}}=\sigma_{\text {para }}^{\mathrm{X}}$ and at position $\mathrm{C}-5$, $\sigma_{\mathrm{x}}^{\mathrm{NH}}=\sigma_{m e t a}^{\mathrm{x}}$.

Since the fundamental component of the effect caused by a given substituent at meta position is essentially inductive, whereas for para-substitution it is composed of both inductive and mesomeric effects; it is evident that $\sigma_{\text {ef }}$ actually represents, to a large extent, the result of the mesomeric effect of a substituent on the entire tautomeric system. A negative value of $\sigma_{\text {ef }}$ indicates a positive mesomeric (or electron-donating) effect, and conversely a positive value implies a negative mesomeric (or electron-withdrawing) effect. For several substituents, eq. [5] becomes eq. [6] (see ESI†):

$$
\log K_{\mathrm{T}}=\rho\left(\sum \sigma_{\mathrm{i}}^{\mathrm{OH}}-\sum \sigma_{\mathrm{i}}^{\mathrm{NH}}\right)+\mathrm{c}=\rho \sigma_{\mathrm{ef}}^{\mathrm{T}}+\mathrm{c}
$$

where now $\sigma_{\mathrm{ef}}^{\mathrm{T}}=\sum \sigma_{\mathrm{ef}}^{\mathrm{i}}=\sum \sigma_{\mathrm{i}}^{\mathrm{OH}}-\sum \sigma_{\mathrm{i}}^{\mathrm{NH}}$ and $c$ is a constant; in principle different from zero, because of the different termini of the tautomeric system.

The most important conclusion arising from this analysis is that not only the electronic nature of a substituent is responsible for the adopted structure of either imine or enamine, but also the position it occupies within the tautomeric system. ${ }^{34}$

Moreover, eqs. [5] and [6] can be used to interrogate the effect of substituents on the tautomeric equilibrium; a point that requires to experimentally determine the corresponding constants $\left(K_{\mathrm{T}}\right)$. To this end, spectroscopic data derived from ${ }^{1} \mathrm{H}$ and ${ }^{13} \mathrm{C}$ NMR spectra were obtained. When an equilibrium exists between two tautomeric forms in solution, the observed chemical shifts are an average $\left(\delta_{\text {exp }}\right)$ of those corresponding to the imine $\left(\delta_{i}\right)$ and enamine $\left(\delta_{e}\right)$ "pure" forms. If $\mathrm{n}_{\mathrm{i}}$ and $\mathrm{n}_{\mathrm{e}}$ are the populations of molecules with imine and enamine structure, respectively, one can formulate eq. [7]:

$$
\delta_{\text {exp }}=n_{i} \delta_{i}+n_{e} \delta_{e}, \text { where } \mathrm{n}_{\mathrm{i}}+\mathrm{n}_{\mathrm{e}}=1
$$

Provided that the magnitudes of $\delta_{i}$ and $\delta_{e}$ are known, the tautomerization constant of the imine-enamine equilibrium, defined as $K_{\mathrm{T}}=[$ enamine $] /[$ imine $]=\mathrm{n}_{\mathrm{e}} / \mathrm{n}_{\mathrm{i}}$, will be determined by:

$$
K_{T}=n_{e} / n_{i}=\left(\delta_{\text {exp }}-\delta_{i}\right) /\left(\delta_{e}-\delta_{\text {exp }}\right)
$$

This expression is similar to that used by Alarcón et al. ${ }^{35}$ In any case, it is not immediately obvious whether the chosen values of $\delta_{i}$ and $\delta_{e}$ do actually correspond to "pure" imine or enamine forms, which represents the weak point of this approach. Data collected in Table 6 for imines 8-15 have been used to assess the electronic effect that substituents exert on the tautomeric equilibrium, as well as on the shifts of atoms involved in the tautomeric system.

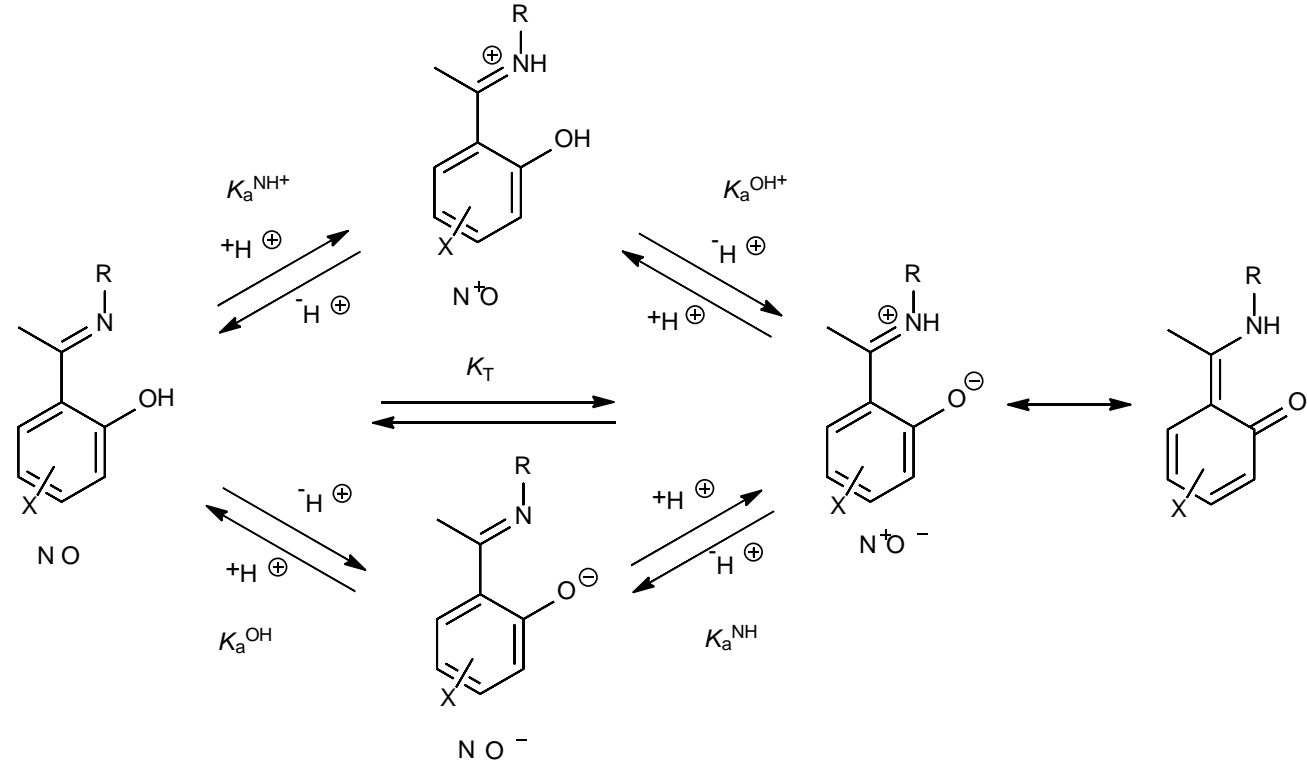

Scheme 5 Proton transfer equilibria for phenol-imine and keto-enamine tautomers. 
Table 6 Substituent effects and tautomeric constants from spectroscopic data of 8-15

\begin{tabular}{cccccccccc}
\hline Compound & $\mathbf{X}$ & $\boldsymbol{\sigma}_{\mathrm{OH}}$ & $\boldsymbol{\sigma}_{\mathrm{NH}}$ & $\boldsymbol{\sigma}_{\mathrm{ef}}{ }^{\mathrm{b}}$ & $\boldsymbol{\delta}_{\mathrm{CN}}$ & $\boldsymbol{\delta}_{\mathrm{OH}}$ & $\boldsymbol{\delta}_{\mathrm{c} 2}$ & $\boldsymbol{K}_{\mathrm{T}^{\mathrm{c}}}$ & $\log _{\boldsymbol{T}_{\mathrm{T}}}$ \\
\hline $\mathbf{8}$ & $\mathrm{H}$ & 0.00 & 0.00 & 0.00 & 172.7 & 16.7 & 164.8 & 0.84 & -0.08 \\
$\mathbf{9}$ & $5-\mathrm{Br}$ & 0.26 & 0.37 & -0.11 & 172.5 & 17.0 & 165.6 & 0.94 & -0.03 \\
$\mathbf{1 0}$ & $5-\mathrm{OMe}$ & -0.28 & 0.10 & -0.38 & 171.9 & 15.8 & 157.5 & 0.24 & -0.61 \\
$\mathbf{1 1}$ & $5-\mathrm{Cl}$ & 0.24 & 0.37 & -0.13 & 172.5 & 16.9 & 165.0 & 0.86 & -0.07 \\
$\mathbf{1 2}$ & $5-\mathrm{NO}_{2}$ & $1.27 \mathrm{~d}$ & 0.71 & 0.56 & 176.1 & 16.6 & 178.4 & 14.92 & 1.17 \\
$\mathbf{1 3}$ & $5-\mathrm{F}$ & 0.15 & 0.34 & -0.19 & 171.8 & 16.4 & 160.5 & 0.43 & -0.37 \\
$\mathbf{1 4}$ & $5-\mathrm{Br}, 3-\mathrm{NO}_{2}$ & 1.50 & 1.64 & -0.14 & 175.7 & 16.7 & 165.3 & 0.90 & -0.05 \\
$\mathbf{1 5}$ & $4,5-(\mathrm{OMe})_{2}$ & -0.18 & -0.18 & 0.00 & 171.1 & 16.5 & 166.9 & 1.12 & 0.05 \\
\hline
\end{tabular}

an DMSO- $d_{6} .{ }^{\mathrm{b}} \sigma_{\mathrm{ef}}=\sigma_{\mathrm{OH}}-\sigma_{\mathrm{NH}} \cdot{ }^{c} \delta_{\mathrm{e}}=180.2 \mathrm{ppm}, \delta_{\mathrm{i}}=152.0 \mathrm{ppm} .{ }^{\mathrm{d}} \sigma_{\mathrm{OH}}{ }^{-}$.

Since the accurate magnitudes of $\delta_{i}$ and $\delta_{e}$ for 2hydroxyacetophenone imines are unknown, the minimum (152.0 $\mathrm{ppm})^{35}$ and maximum $(180.2 \mathrm{ppm})^{34}$ values found for imines/enamines derived from salicylaldehydes were taken as references. Eq. [5] is then transformed into [9]:

$$
\log K_{\mathrm{T}}=\log \frac{\delta_{\text {exp }}-152.00}{180.18-\delta_{\text {exp }}}=\rho \sigma_{\text {ef }}+\mathrm{c}
$$

A good linear relationship can be obtained by plotting $K_{\mathrm{T}}$ data versus $\sigma_{\text {ef }}$ (Figure 6), thus proving a reliable influence of substituent effects on the tautomeric balance for this kind of acetophenone derivatives. Since $c \sim 0.1$, when $\sigma_{\mathrm{ef}} \geq 0, K_{\mathrm{T}}>1$ and the enamine structure predominates; however, if $\sigma_{\mathrm{ef}} \leq 0, K_{\mathrm{T}}<1$ and the imine structure constitutes the prevalent tautomer.

On the other hand, the influence of electronic factors on the tautomeric equilibria can be inferred from the chemical shifts of atoms participating in the imine/enamine skeleton, in particular phenolic proton and carbon. Thus, data fit well to a linear correlation by plotting the chemical shifts of the phenolic carbon (C-2) against $\sigma_{\text {ef }}$ (Figure 7).

The goodness of such fit appears to be logical because the C-2 atom belongs not only to the tautomeric system but also to the aromatic ring, and the electronic effects should be conveyed through delocalized $\pi$-bonds. The representation of chemical shifts of the iminic carbon versus $\sigma_{\mathrm{OH}}$ leads to a fine relationship $(r=0.9565)$ (Figure 8). On the other hand, the representation against $\sigma_{\mathrm{NH}}$ (Figure S46) leads to a poorer correlation ( $r=0.8241)$, which improves significantly by removing data from compound $12(r=0.9441)$.

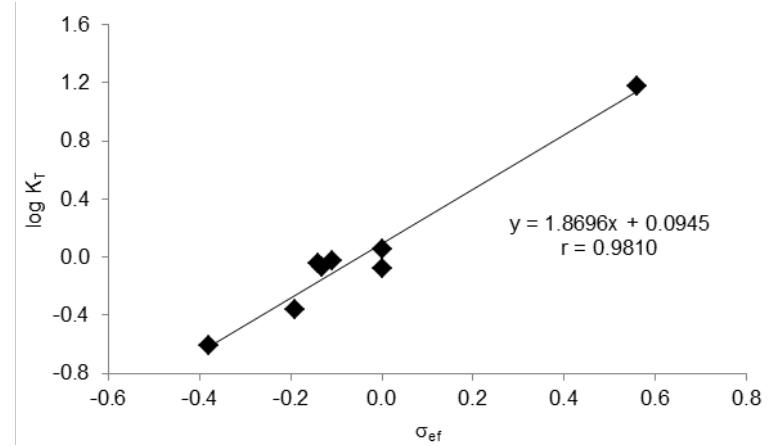

Fig. 6 Linear correlation between tautomeric equilibrium constants and electronic effects of substituents for compounds 8-15.

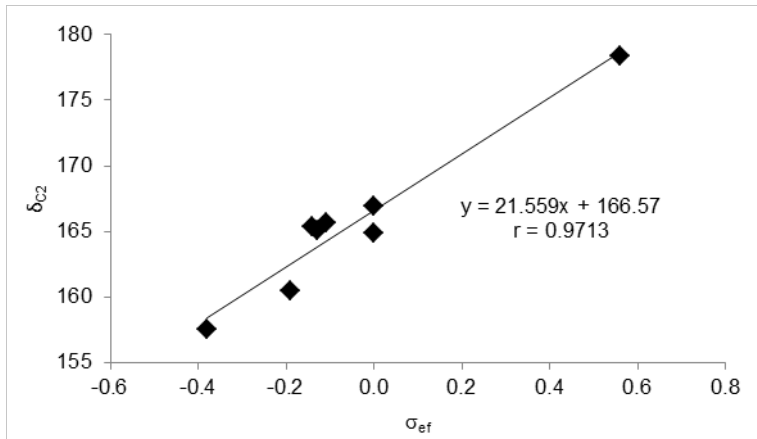

Fig. 7 Linear correlation between chemical shifts $\left(\delta_{\mathrm{c}-2}\right)$ and electronic effects of substituents for compounds 8-15.

Because of chemical shifts have been previously used to determine the corresponding $K_{\mathrm{T}}$ values, linear relationships could be expected among such parameters. Figure S47 evidences this issue, where almost complete linearity is observed when log $K_{\mathrm{T}}$ is plotted versus the chemical shifts of C-2 $(r=0.9942)$. The resulting eq. [10] can be applied to predicting new $K_{\mathrm{T}}$ data and especially for C-2 values close to $\delta_{\mathrm{i}}$ and $\delta_{\mathrm{e}}$.

$$
\log K_{\mathrm{T}}=0.0854 \delta_{\mathrm{C} 2}-14.126
$$

\section{Pseudo-aromaticity in acetophenone imines}

Like in related systems, namely substituted salicylaldehydes, the generation of six-membered pseudo-rings in acetophenone imines

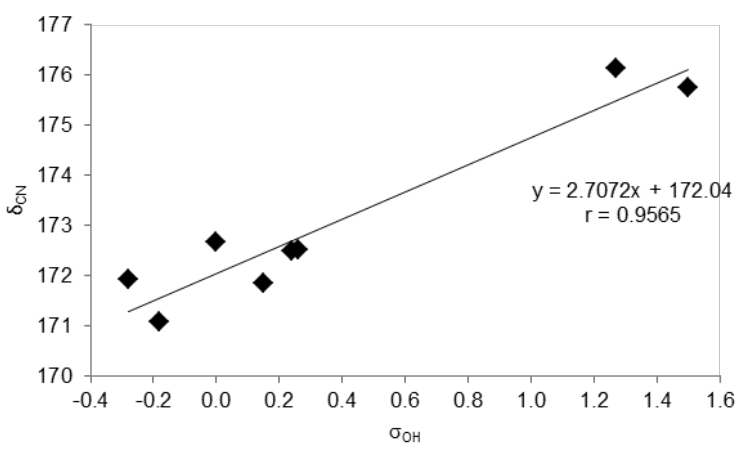

Fig. 8 Linear correlation between chemical shifts $\left(\delta_{\mathrm{C}=\mathrm{N}}\right)$ and electronic effects of substituents (plotted against $\sigma_{\mathrm{OH}}$ ) for compounds 8-15. 
due to a strong intramolecular hydrogen bond, points to additional electronic delocalization (pseudo-aromaticity), for which the concept of resonance-assisted hydrogen bonds (RAHB) has been coined, ${ }^{36}$ as these unconventional bonds exhibit unusual downfield proton shifts $\left(\delta_{H}=16-17 \mathrm{ppm}\right) .{ }^{37} \mathrm{It}$ is held that in RAHBs there is a special stability caused by partial delocalization of the $\pi$-electrons through single and double conjugated bonds. According to the original definition proposed by Gilli and associates, the interplay between the hydrogen bond and $\pi$-delocalization of heteroconjugate systems strengthens the hydrogen bond. ${ }^{36}$ Others authors have however expressed some criticisms and suggest that the primary cause accounting for stability involves the $\sigma$-skeleton rather than the $\pi$-electron delocalization. ${ }^{38}$ The quasi- ring formed through the $\mathrm{H}$-bridge can partially adopt the role of a typical aromatic ring. Gilli et al. proposed that these strong hydrogen bonds have significant covalent character, ${ }^{39}$ thereby extending the concept of aromaticity to pseudo-aromatic, or quasiaromatic, rings, even though ordinary hydrogen bonds are believed to be largely electrostatic in nature. ${ }^{40}$

The $\pi$-electron delocalization assisted by hydrogen bonding can be evaluated in terms of geometrical parameters. ${ }^{41}$ Several aromaticity indices ${ }^{42-48}$ have been introduced to this purpose, often showing complementary views and similar conclusions. We have used them in previous studies dealing with delocalization of pseudo-heterocyclic tautomers of Schiff bases derived from salicylaldehydes ${ }^{49}$ and 2-arylsubstituted acroleins. ${ }^{22}$ The HOMA index ${ }^{46}$ is one of the most popular and effective indices of aromaticity based on structural criteria. ${ }^{50} \mathrm{We}$ have calculated HOMA indices for tautomers 8/16, 10/18 and 12/20 in the gas phase at the B3LYP/6-311G(d,p) level.

Data collected in Table 7 show low HOMA values in the pseudo-ring of bridged imines $(<0.48)$, consistent with a poor electron delocalization. During tautomerization the index increases in the transition state ( $\sim 0.8)$ as well as in the final enamine structure ( $\sim 0.9)$. Accordingly, pseudo-heterocycles of transition and enamine structures exhibit a high degree of delocalization. The hydrogen bond is essential for this delocalization to occur. When hydrogen bond is removed in 8,10 , and 12 , through $90^{\circ}$-rotation of the $\mathrm{C} 7-\mathrm{OH}$ bond, the resulting imines 34-36 show HOMA values close to zero for the pseudo-heterocycle (Table 7).

In order to determine how the solvent affects the electronic delocalization, the HOMA indices were calculated in DMSO, as most NMR spectra were recorded in that solvent. The influence of solvation on the $\pi$-delocalization was assessed by optimizing structures at the B3LYP/6-311G(d,p) level with the SMD model $(\varepsilon D M S O=46.8)$, and then re-calculating the HOMA values. The inclusion of bulk solvation does not produce a significant alteration of the delocalization index, and newly data show an increase of $\pi$ electron delocalization in the TSs relative to the parent imine tautomers. Finally, it is relevant to note the high level of delocalization (pseudo-aromaticity) shown by the pseudoheterocycle of enamines in both the gas phase and DMSO, giving HOMA indices comparable to that of benzene.
Table 7 HOMA indices calculated for the tautomerization of 8/16, 10/18, $12 / 20$ and $34-36^{\mathrm{a}, \mathrm{b}}$

\begin{tabular}{ccccc} 
& Het $^{\mathrm{c}}$ & Car $^{\mathrm{c}}$ & Het $^{\mathrm{d}}$ & Car $^{\mathrm{d}}$ \\
\hline $\mathbf{8}$ & 0.45 & 0.98 & 0.42 & 0.98 \\
$\mathrm{TS}_{8 / 16}$ & 0.79 & 0.93 & 0.70 & 0.95 \\
$\mathbf{1 6}$ & 0.85 & 0.87 & 0.83 & 0.88 \\
$\mathbf{3 4}$ & 0.14 & 0.99 & 0.15 & 0.99 \\
\hline $\mathbf{1 0}$ & 0.43 & 0.98 & 0.38 & 0.98 \\
$\mathbf{T S}_{10 / 18}$ & 0.80 & 0.93 & 0.71 & 0.95 \\
$\mathbf{1 8}$ & 0.87 & 0.86 & 0.83 & 0.90 \\
$\mathbf{3 5}$ & 0.09 & 0.99 & 0.12 & 0.99 \\
\hline $\mathbf{1 2}$ & 0.33 & 0.98 & 0.50 & 0.98 \\
$\mathbf{T S}_{12 / 20}$ & 0.76 & 0.93 & 0.69 & 0.95 \\
$\mathbf{2 0}$ & 0.83 & 0.86 & 0.80 & 0.87 \\
$\mathbf{3 6}$ & 0.22 & 0.99 & 0.27 & 0.99 \\
\hline
\end{tabular}

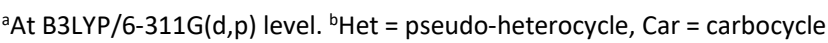
fused to the pseudo-heterocycle. In the gas phase. dincluding the solvent effect (SMD model, DMSO as solvent).

\section{Conclusions}

A new family of chiral imines has been prepared by direct condensation of substituted acetophenones with D-glucamine. Although in the solid state they exhibit an imine structure, in solution they exist in equilibrium with their corresponding enamine tautomers. The tautomeric equilibrium has been studied by both theory and experiment. The calculated activation free energies are very small $\left(\Delta G^{\ddagger}<2.1 \mathrm{kcal} \mathrm{mol}{ }^{-1}\right)$ for the imine $\rightarrow$ enamine transformation and negative $\left(\Delta \mathrm{G}^{\ddagger}<0 \mathrm{kcal} \mathrm{mol}^{-1}\right)$ for the inverse enamine $\rightarrow$ imine tautomerization. Transition states with high imaginary vibration frequencies $\left(-1100 \mathrm{~cm}^{-1}\right.$ to $\left.-875 \mathrm{~cm}^{-1}\right)$ are responsible for the existence of negative activation energies. The strength of the intramolecular hydrogen bonding, between $15 \mathrm{kcal}$ $\mathrm{mol}^{-1}$ and $10 \mathrm{kcal} \mathrm{mol}^{-1}$, correspond to strong hydrogen bonds.

Good to excellent linear free-energy relationships could be obtained by plotting $\ln K_{\mathrm{T}}$ or $\delta_{\mathrm{C} 2} v s$. the appropriate $\sigma_{\mathrm{ef}}\left(=\sigma_{\mathrm{X}}^{\mathrm{OH}}-\sigma_{\mathrm{X}}^{\mathrm{NH}}\right)$ values $(r$ $=0.981$ or 0.971$)$. Furthermore, there exists a good correlation between the chemical shift of the imine carbon $\left(\delta_{\mathrm{C} 2}\right)$ and $\sigma_{\mathrm{OH}}(r=$ 0.957). These results show the close relationship between the electronic effect of the substituents and the tautomeric phenoliminic-ketoenamine equilibrium exhibited by compounds 815 in solution. The HOMA values show that the electronic delocalization in the pseudo heterocyclic ring increases significantly when passing from a phenoliminic ( 0.45$)$ to ketoenamine structure $(\sim 0.85)$. For this delocalization, the existence of the intramolecular hydrogen bridge constitutes an essential feature. When this does not exist, HOMA values become negligible $(<0.2)$.

From a structural viewpoint, it is worth pointing out that acetylation of imines with acetic anhydride/pyridine, gives rise to unexpected mixtures of an enamine, with a full acyclic framework, and a $\mathrm{N}$-acetyl1,3-oxazolidine, with a chiral ring. Single-crystal X-ray diffraction shows that four molecules are present in the unit cell: two of enamine and two of $\mathrm{N}$-acetyl-1,3-oxazolidine derivatives. The amide bonds of both structures show $E$ configuration; however, in solution a balance is established between the $E$ and $Z$ rotamers. 


\section{Experimental section}

All solvents and reagents were obtained from commercial suppliers and used as received. General methods describing experimental and synthetic procedures along with crystallographic and spectroscopic data are reported in ESIt.

\section{Computational analyses.}

All calculations were carried out using the Gaussian09 package. ${ }^{19}$ Geometries were optimized using the global-hybrid meta-GGA functional M06-2 $\mathrm{X}^{17}$ or the B 3 LYP hybrid functional ${ }^{21}$ in combination with the Pople $6-311 \mathrm{G}(\mathrm{d}, \mathrm{p})$ basis set. ${ }^{18}$ Geometries were optimized with inclusion of solvation effects in water using the SMD method. ${ }^{20}$ All saddle points linking specific reactant and products through the reaction path were verified using intrinsic reaction coordinate (IRC) analysis. Frequency calculations were carried out at $298.15 \mathrm{~K}$ at the above-mentioned level of theory. Saddle points and energy minima were characterized by one or none imaginary frequencies, respectively.

\section{General procedure for Schiff bases synthesis}

To a solution of D-glucamine $(1.8 \mathrm{~g}, 10.0 \mathrm{mmol})$ in water $(13 \mathrm{~mL})$ was slowly added a solution of the corresponding acetophenone (10.0 $\mathrm{mmol}$ ) in the minimum volume of methanol. The mixture was kept under stirring at $90{ }^{\circ} \mathrm{C}$ for 20 minutes. It was left to cool to room temperature and subsequently stored at $5 \stackrel{\circ}{ } \mathrm{C}$. The solid formed was filtered and washed with cold water, cold ethanol and diethyl ether. The product was further recrystallized from ethanol.

\section{General acetylation procedure}

Acetic anhydride ( $4.5 \mathrm{~mL}$ ) was added, under stirring, to a suspension of the corresponding imine $(3.0 \mathrm{mmol})$ in pyridine $(4.0 \mathrm{~mL})$ at room temperature. After $24 \mathrm{~h}$, the mixture was poured into ice-water crystallizing a solid that was filtered and washed with ethanol and diethyl ether. In the cases in which precipitation failed, the aqueous phase was extracted with $\mathrm{CH}_{2} \mathrm{Cl}_{2}(2 \times 60 \mathrm{~mL})$. Then, the organic fraction was washed successively with aqueous solutions of $1 \mathrm{M} \mathrm{HCl}$ $(2 \times 60 \mathrm{~mL})$, saturated $\mathrm{NaHCO}_{3}(2 \times 60 \mathrm{~mL})$, and finally distilled water $(2 \times 60 \mathrm{~mL})$. The organic layer was dried over anhydrous $\mathrm{MgSO}_{4}$ and evaporated to dryness.

\section{Conflicts of interest}

The authors declare no conflict of interest.

\section{Acknowledgements}

This work was supported by the Junta de Extremadura (Consejería de Economía, Ciencia y Agenda Digital) and Fondo Europeo de Desarrollo Regional (Grants IB16167 and GR18015). We thank CenitS and Computaex Foundation for allowing us to use supercomputer LUSITANIA.

\section{Notes and references}

1 Y. Ezuri, S. Maruo, K. Miyazaki, T. Seto, N. Yamada, M. Sugiyama, M. Itoh and T. Nakamura, Agric. Biol. Chem., 1989, 53, 1421-1422.

2 K. Daigo, Y. Inamori and T. Takemoto, Chem. Pharm. Bull. 1986, 34, 2243-2246.

3 a) R. B. Silverman and M. W. Holladay, The Organic Chemistry of Drug Design and Drug Action, 3rd. Ed., Elsevier, Amsterdam, 2014, pp. 189-192. b) J. Clayden, N. Greeves, S. Warren and P. Wothers, Organic Chemistry, Oxford University Press, Oxford, 2001, pp. 1407-1408.

4 D. T. Coxon, A. M. C. Davies, G. R. Fenwick and R. Self, Tetrahedron Lett., 1980, 21, 495-498.

5 M. E. Tate, J. G. Ellis, A. Kerr, J. Tempe, K. E. Murray and K. J. Shaw, Carbohydr. Res., 1982, 104, 105-120.

6 M. Ávalos, R. Babiano, P. Cintas, J. L. Jiménez, M. E. Light, J. C. Palacios and E. M. S. Pérez, J. Org. Chem., 2008, 73, 661-672. b) T. Lanyon-Hogg, M. Ritzefeld, N. Masumoto, A. I. Magee, H. S. Rzepa, E. W. Tate, J. Org. Chem., 2015, 80, 4370-4377.

7 R. F. Martínez, M. Avalos, R. Babiano, P. Cintas, J. L. Jiménez, M. E. Light, J. C. Palacios and E. M. S. Pérez, Tetrahedron, 2008, 64, 6377-6386.

8 E. Matamoros, PhD dissertation, Universidad de Extremadura, Badajoz, Spain, 2016.

9 a) J. Arunpanichlert, V. Rukachaisirikul, S. Phongpaichit, O. Supaphon and J. Sakayaroj, Tetrahedron, 2015, 71, 882-888. b) For the most comprehensive treatment of hydroxyacetophenones: R. Martin, Handbook of Hydroxyacetophenones. Preparation and Physical Properties, Springer, Berlin, 2005, Vol. 2, pp. 214, 260, 316, 376 and references therein.

10 For the influence of imine-enamine tautomerism on biological activity of other Schiff bases: a) P. Przybylski, A. Huczynski, K. Pyta, B. Brzezinski and Franz Bartl, Curr. Org. Chem., 2009, 13, 124-148. b) E. Ritter, P. Przybylski, B. Brzezinski and Franz Bartl, Curr. Org. Chem., 2009, 13, 241-249. c) C. M. da Silva, D. L. da Silva, L. V. Modolo, R. B. Alves, M. A. de Resende, C. V. B. Martins and Â. de Fátima, J. Advanced Res., 2011, 2, 1-8.

11 P. E. Hansen and A. Filarowski, J. Mol. Struct., 2004, 707, 6981.

$12 \mathrm{~K}$. Nakanishi and P. Solomon, Infrared Absorption Spectroscopy, 2nd Ed., Holden-Day, San Francisco, 1997, pp. 42.

13 M. Avalos, R. Babiano, P. Cintas, J. L. Jiménez, J. C. Palacios and C. Valencia, Tetrahedron, 1994, 50. 3273-3296.

14 L. M. Jackman and S. Sternhell, Applications of Nuclear Magnetic Resonance Spectroscopy in Organic Chemistry, 2nd Ed., Pergamon Press, Oxford, 1969, pp. 277-279.

15 Crystal data have been deposited with the Cambridge Crystallographic Data Centre (registry number: CCDC1955191). They can be obtained free of charge from The Cambridge Crystallographic Data Centre via www.ccdc.cam.ac.uk/data request/cif.

16 a) R. G. Parr and W. Yang, Density-functional theory of atoms and molecules, Oxford University Press, Oxford, 1989. b) A. D. Becke, J. Chem. Phys., 1992, 96, 2155-2160. c) P. M. W. Gill, B. G. Johnson, J. A. Pople and M. Frisch, Chem. Phys. Lett., 1992, 197, 499-505. d) P. J. Stephens, F. J. Devlin, M. J. Frisch and C. F. Chabalowski, J. Phys. Chem., 1994, 98, 11623-11627.

17 Y. Zhao and D. G. Truhlar, Theor. Chem. Acc., 2008, 120, 215241.

18 a) A. D. McLean and G. S. Chandler, J. Chem. Phys., 1980, 72, 5639-5648. b) K. Raghavachari, J. S. Binkley, R. Seeger and J. A. Pople, J. Chem. Phys., 1980, 72, 650-654.

19 M. J. Frisch, G. W. Trucks, H. B. Schlegel, G. E. Scuseria, M. A. Robb, J. R. Cheeseman, G. Scalmani, V. Barone, B. Mennucci, G. A. Petersson, H. Nakatsuji, M. Caricato, X. Li, H. P. 
Hratchian, A. F. Izmaylov, J. Bloino, G. Zheng, J. L. Sonnenberg, Hada, M. Ehara, K. Toyota, R. Fukuda, J. Hasegawa, M. Ishida, T. Nakajima, Y. Honda, O. Kitao, H. Nakai, T. Vreven, J. A Montgomery Jr, J. E. Peralta, F. Ogliaro, M. Bearpark, J. J. Heyd, E. Brothers, K. N. Kudin, V. N. Staroverov, R. Kobayashi, J. Normand, K. Raghavachari, A. Rendell, J. C. Burant, S. S. lyengar, J. Tomasi, M. Cossi, N. Rega, J. M. Millam, M. Klene, J. E. Knox, J. B. Cross, V. Bakken, C. Adamo, J. Jaramillo, R. Gomperts, R. E. Stratmann, O. Yazyev, A. J. Austin, R. Cammi, C. Pomelli, J. W. Ochterski, R. L. Martin, K. Morokuma, V. G. Zakrzewski, G. A. Voth, P. Salvador, J. J. Dannenberg, S Dapprich, A. D. Daniels, Ö. Farkas, J. B. Foresman, J. V. Ortiz, J. Cioslowski and D. J. Fox, Gaussian 09, Revision A.1, Gaussian Inc., Wallingford, CT, 2009.

20 A. V. Marenich, C. J. Cramer and D. G. Truhlar, J. Phys. Chem. B, 2009, 113, 6378-6396.

21 a) C. Lee, W. Yang and R. G. Parr, Phys. Rev. B, 1988, 37, 7582. b) A. D. Becke, J. Chem. Phys., 1993, 98, 5648-5652.

22 M. P. Romero-Fernández, M. Ávalos, R. Babiano, P. Cintas, J. L. Jiménez and J. C. Palacios, J. Phys. Chem. A, 2015, 119, 525534.

23 P. Gilli, V. Bertolasi, L. Pretto, A. Lyčka and G. Gilli, J. Am. Chem. Soc., 2002, 124, 13554-13567.

24 M. P. Romero-Fernández, M. Ávalos, R. Babiano, P. Cintas, J. L. Jiménez and J. C. Palacios, Tetrahedron, 2016, 72, 95-104.

25 E. Matamoros, P. Cintas and J. C. Palacios, Org. Biomol. Chem., 2019, 17, 6229-6250.

26 M. Flores-Leonar, N. Esturau-Escofet, J. M. Méndez-Stivalet, A. Marín-Becerra and C. Amador-Bedolla, J. Mol. Struct., 2011, 1006, 600-605

27 T. Schaefer, J. Phys. Chem., 1975, 79, 1888-1890.

28 a) G. R. Desiraju and T. Steiner, The Weak Hydrogen Bond in Structural Chemistry and Biology, $\mathrm{IUCr}$ Monographs on Crystallography Vol. 9, Oxford University Press, New York, 1999, pp. 12-14. b) R. Parthasarathi and V. Subramanian, Hydrogen Bonding-New Insights (ed.: S. J. Grabowski), Springer, Berlin, 2006, pp. 2-50. c) An older and highly cited review by J. Emsley (Chem. Soc. Rev., 1980, 9, 91-124), entitled "Very strong hydrogen bonding", indicated that for weak or normal $\mathrm{H}$-bonds the strength is less than $12 \mathrm{kcal} / \mathrm{mol}$.

29 P. E. Hansen, A. Koch, E. Kleinpeter Tetrahedron Lett. 2018 59, 2288-2292.

30 R. N. Musin and Y. H. Mariam, J. Phys. Org. Chem., 2006, 19, 425-444.

31 a) K. Tabei and E. Saitou, Bull. Chem. Soc. Jpn., 1969, 42, 14401443. b) B. Ž. Jovanovic, M. Mišic-Vukovic, A. D. Marinkovic and V. Vajs, J. Mol. Struct., 1999, 482-483, 375-378. c) B. Ž. Jovanovic, A. D. Marinkovic, F. H. Assaleh and J. Csanádi, J. Mol. Struct., 2005, 742-747, 411-416.

32 For a comprehensive review: E. D. Raczyńska, W. Kosińska, B. Ośmialowski and R. Gawinecki, Chem. Rev., 2005, 105, 35613612.

33 a) G. Gilli and P. Gilli, J. Mol. Struct., 2000, 552, 1-15. b) P. Gilli, V. Bertolasi, L. Pretto and G. Gilli, J. Mol. Struct., 2006, 790, 40-49. c) P. Gilli, L. Pretto and G. Gilli, J. Mol. Struct., 2007, 844-845, 328-339.

34 R. F. Martínez, PhD Dissertation, Universidad de Extremadura, Badajoz, Spain, 2010.

35 S. H. Alarcón, D. Pagani, J. Bacigalupo and A. C. Olivieri, J. Mol. Struct., 1999, 475, 233-240.

36 G. Gilli, F. Bellucci, V. Ferretti and V. Bertolasi, J. Am. Chem. Soc., 1989, 111, 1023-1028.

37 V. Bertolasi, P. Gilli, V. Ferretti and G. Gilli, J. Am. Chem. Soc. 1991, 113, 4917-4925.

38 a) I. Alkorta, J. Elguero, O. Mó, M. Yañez and J. E. del Bene Mol. Phys., 2004, 102, 2563-2574. b) P. Sanz, O. Mó, M. Yañez and J. Elguero, Chem. Phys. Chem., 2007, 8, 1950-1958. c) P. Sanz, O. Mó, M. Yañez and J. Elguero, J. Phys. Chem. A, 2007,
11, 3585-3591. d) P. Sanz, O. Mó, M. Yañez and J. Elguero, Chem. Eur. J., 2008, 14, 4225-4232.

39 P. Gilli, V. Bertolasi, V. Ferretti and G. Gilli, J. Am. Chem. Soc., 1994, 116, 909-915.

40 G. A. Jeffrey, An Introduction to Hydrogen Bonding, Oxford University Press, New York, 1997.

41 T. M. Krygowski, H. Szatylowicz, O. A. Stasyuk, J. Dominikowska and M. Palusiak, Chem. Rev., 2014, 114, 63836422.

42 a) C. W. Bird, Tetrahedron, 1985, 41, 1409-1414. b) C. W. Bird Tetrahedron, 1986, 42, 89-92. c) C. W. Bird, Tetrahedron, $1993,49,8441-8448$.

43 S. I. Kotelevskii and O. V. Prezhdo, Tetrahedron, 2001, 57 5715-5729.

44 A. F. Pozharskii, Chem. Heterocycl. Compd., 1985, 21, 717-749.

45 M. Mezei and D. L. Beveridge, Ann. NY. Acad. Sci., 1986, 482 1-23.

46 T. M. Krygowski, J. Chem. Inf. Comput. Sci., 1993, 33, 70-78.

47 a) E. D. Raczynska, K. Duczmal and M. Hallmann, Polish J. Chem., 2007, 81, 1655-1666. b) E. D. Raczynska, M. Hallmann and K. Duczmal, Polish J. Chem., 2008, 82, 1077-1090. c) E. D. Raczynska, M. Hallmann, K. Kolczynska and T. Stepniewski, Symmetry, 2010, 2, 1485-1509.

48 C. P. Frizzo and M. A. P. Martins, Struct. Chem., 2012, 23, 375 380.

49 R. F. Martínez, M. Ávalos, R. Babiano, P. Cintas, J. L. Jiménez, M. E. Light and J. C. Palacios, Eur. J. Org. Chem., 2011, 3137 3145 .

50 a) P. V. R. Schleyer, Chem. Rev., 2001, 101, 1115-1118. b) T. M. Krygowski and M. K. Cyrański, Chem. Rev., 2001, 101, 13851420. c) E. Matito, M. Duran and M. Solà, J. Chem. Phys., 2005, 122, $014109(1-8)$. 